\title{
Attitudes of Consumers from Autonomous Province of Vojvodina toward Advertising through Sport for the Question: How Often Do Consumers Purchase Sporting Goods
}

\author{
Zoran Milosevic ${ }^{1}$, Dusko Bjelica ${ }^{2}$ and Bojan Masanovic ${ }^{2}$ \\ 'University of Novi Sad, Faculty of Sport and Physical Education, Novi Sad, Serbia, ${ }^{2}$ University of Montenegro, Faculty for Sport and Physical \\ Education, Niksic, Montenegro
}

\begin{abstract}
This research was aimed at gaining relevant knowledge about the attitudes of the consumers from the Autonomous Province of Vojvodina toward advertising through sport for the question how often do consumers purchase sporting goods. The sample included 451 students from Faculty of Sport and Physical Education, Faculty of sport and tourism in Novi Sad and Chemical, Biotechnology and Medicine Department in Subotica, divided into six subsamples: consumers who do not purchase sporting goods at all, then consumers who purchase sporting goods less than once a month, next 1-3 times a month, 4-6 times a month, 7-9 times a month, as well as consumers who purchase sporting goods more than 10 times a month. The sample of variables contained the system of three general attitudes which were modelled by the seven-point Likert scale. The results of the measuring were analysed by multivariate analysis (MANOVA), univariate analysis (ANOVA) and Post Hoc test. Based on the statistical analyses it was found that significant differences occur at multivariate level, as well as among all three variables at a significance level of $(p=.000)$. Hence, it is interesting to highlight that it was found that significant differences showed up between the consumers who purchase sporting goods. The significant differences were found in two out of three variables, while the consumers who purchase sporting goods less than 3 times a month had much more negative attitudes toward advertising through sport.
\end{abstract}

Key words: attitudes, advertising, sporting goods, Vojvodina

\section{Introduction}

Guided by the fact that investment in advertising through sport as part of the corporate marketing strategy is continually growing, the demand for research in this area has been generated in order to determine the best prospects of it (Muratovic, Bjelica, \& Popovic, 2014). A systematic study of consumers' attitudes toward advertising was rooted in the Bauer and Greyser's studies (Popovic, 2011), while the one who made major contribution to science when it comes to advertising through sport was Pyun (Klacar \& Popovic, 2010), who has conducted a research in which he constructed a new model for consumer behaviour-related research into sports advertising, which enabled various researchers to examine consumers' attitudes and beliefs about advertising through sport around the world, and compare their conclusions. In studies investigating attitudes towards general advertising in the 1940s and 1950s, according to Bauer and Greyser (Popovic, Bjelica, Jaksic, \& Georgiev, 2013, Popovic, 2015, Popovic \& Milasinovic, 2016) it has been concluded that consumers generally have positive attitudes. However, by comparing the results with recent research (Bjelica \& Popovic, 2011, Popovic, 2011b; Popovic, Matic, Milasinovic, Jaksic, \& Bjelica, 2015a; Popovic, Matic, Milasinovic, Jaksic, \& Bjelica 2015b; Popovic, Jaksic, Matic, Bjelica, \& Maksimovic, 2015), it has been found that consumers have

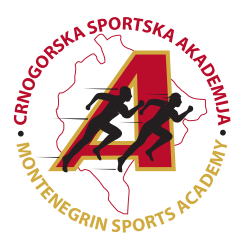

Correspondence:

B. Masanovic

University of Montenegro, Faculty for Sport and Physical Education, Niksic, Montenegro

E-mail: bojanma@ucg.ac.me 
a more and more negative attitude toward advertising. After a while, Shavitt and his associates (Bjelica \& Popovic, 2011) have found that respondents in their study have much more positive attitudes towards advertising than it was the case in previous studies. It is assumed that attitudes vary among respondents, as they differentiate certain types of advertising messages, and Mittal (Popovic, 2011) has found that they have much more negative attitudes towards advertising on television than towards advertising in general. With the increase in negative attitudes toward advertising on television, marketers have had to devise a way to bring back the audience's confidence in television advertisement, and they did this by applying technological innovations such as video recorders which allowed the viewers who are indifferent toward advertising messages, to skip parts that were not interesting to them (Bjelica, Popovic, Jaksic, Hadzic, \& Akpinar, 2014; Bjelica \& Popovic, 2015a; Bjelica \& Popovic, 2015b; Bjelica, Gardasevic, Vasiljevic, \& Popovic, 2016a; Bjelica, Gardasevic, Vasiljevic, \& Popovic, 2016b). Along with the above-mentioned invention, attitudes towards advertising through sport have, again, become much more positive. However, this invention did not allow viewers to skip parts of the program with advertising messages when it comes to watching sports events, as they occurred at the time of the events. Nevertheless, the closeness and affection towards sport and sportsmen over time have aided overcoming the negative attitudes of viewers that they have had when advertising in general in question, which led advertising through sport to take up the place that belongs to it today. The question that arises is how the purchase of sporting goods affects consumers' attitudes toward advertising through sport which is one of the many problems that not many authors have encountered so far (Bajramovic, Zoric, \& Masanovic 2018; Gardasevic, Bajramovic, \& Masanovic, 2018; Milovic, Corluka, \& Masanovic, 2018; Masanovic, 2018; Molnar, Masanovic, \& Bjelica, 2018; Stupar, Gardasevic, \& Masanovic, 2018), and it is the exact goal of this study.

\section{Methods}

The population of this study consisted of the students of the Faculty of Sport and Physical Education, the Faculty of Sport and Tourism in Novi Sad and the High Schools of Vocational Studies for Education of Teachers and Trainers in Subotica who were residents of the Republic of Serbia at the time of the survey, while the sample was organized by combining or decomposing, so that the different properties of said population and the various spaces in which it existed were treated.

The questionnaires were distributed to undergraduate students in printed and electronic form. A total of 470 questionnaires were collected, but 19 questionnaires were excluded from the analysis, since they were not adequately completed, so that 451 respondents (randomly selected students of the Faculty of Sport and Physical Education, Faculty of Sport and
Tourism in Novi Sad and High Schools for Vocational Education for Trainers and Coaches in Subotica) took part in this research. The research instrument was a standardized questionnaire (Popovic, 2011) which consisted of two parts, general attitudes towards sports commercials, and socio-demographic characteristics of respondents when it comes to the frequency of buying sporting goods during one month. The system of variables in this questionnaire consisted of three statements that the respondents needed to evaluate according to the seven-degree Likert scale and the six socio-demographic characteristics of the respondents (not buying at all, less than once a month, 1-3 times per month, 4-6 times per month, 7-9 times per month, and more than 10 times per month). Completing the questionnaire did not take too long, about 10 minutes on average and respondents participated voluntarily in the survey. It is important to point out that the survey was anonymous and that all responses were classified as strictly confident. It is also worth noting that the respondents, in addition to all the above mentioned, had the opportunity to cancel their participation in the survey at any moment, but none of them decided to do so.

Empirical data were analysed using the statistical package for social sciences (SPSS 20.0), and as a first step, descriptive statistics was used for calculating the frequency in the first place, then the arithmetic mean, Standard deviation, as well as the Skewness and Flattening measures (Kurtosis) for each statement. Since the variables in this study were on nonparametric scales, for the detailed analysis that followed, it was necessary to transform them into higher order scales using Blom's method. Then, using the multivariate variance analysis (MANOVA), the univariate variance analysis (ANOVA) and the LSD Post Hoc test, the differences in the general attitudes of the respondents toward advertising through sport in relation to the frequency of buying sporting goods during one month have been found.

\section{Results}

The first table shows descriptive statistics for all three claims that are in relation with the general attitudes of the respondents toward advertising through sport. First of all, the arithmetic mean which reflects the positive values of attitudes when all three claims are concerned is depicted, while the values of standard deviation show that the elements together do not deviate significantly from the arithmetic mean. When it comes to the measures of asymmetry (Skewness) and flattening (Kurtosis), the negative values of asymmetry in all variables show that most of the results are right from the mean, among the higher values, while the negative values of flattening, for all three are variable (GSS1, GSS2 and GSS3), show that the distribution is flatter than normal, i.e., that there are more results accumulated on the distribution tails.

Table 1. General attitudes towards advertising through sport

\begin{tabular}{lcccccc}
\hline & \multirow{2}{*}{ Mean } & \multirow{2}{*}{ S. D. } & \multicolumn{2}{c}{ Skewness } & \multicolumn{2}{c}{ Kurtosis } \\
& & & Statistic & S. E. & Statistic & S. E. \\
\hline GSS1 & 4.80 & 1.637 & -.409 & .115 & -.370 & .229 \\
GSS2 & 5.18 & 1.569 & -.615 & .115 & -.266 & .229 \\
GSS3 & 4.53 & 1.495 & -.244 & .115 & -.245 & .229 \\
\hline
\end{tabular}

Legend: Mean-Arithmetic mean; S.D.-Standard deviation; Skewness-Measures of asymmetry; Kurtosis-Measures of flattening; Statistic-Statistic value; S.E.-Standard error; GSS1-"My general opinion is in favour of advertising through sport"; GSS2-"Generally, I consider advertising through sport a good thing"; GSS3-"Generally, do you like or dislike advertising through sport?" 
In the continuation of this study, comparative statistics of general attitudes towards advertising through sport are shown. They were obtained by using the multivariate variance analysis (MANOVA), the univariate analysis of variance (ANOVA) and the LSD Post Hoc test, in order to determine the difference in the general attitudes of the respondents toward advertising through sport in relation to the frequency of buying sporting goods.
By inspecting the second table which shows the results of the multivariate analysis, it is clearly evident that there is a statistically significant difference in the whole system of the compared parameters in the general attitudes toward advertising through sport in relation to the frequency of buying sporting goods $(\mathrm{p}=.005)$.

Table 2. Multivariate significance of differences in the system of general attitudes towards advertising through sport among respondents with different habits when buying sporting goods in question

\begin{tabular}{|c|c|c|c|c|}
\hline & & $\mathbf{N}$ & Mean & S. D. \\
\hline & Do not buy & 65 & 4.34 & 1.564 \\
\hline & $<1$ & 148 & 4.67 & 1.708 \\
\hline & $1-3$ & 174 & 4.95 & 1.660 \\
\hline \multirow[t]{7}{*}{ GSS1 } & $4-6$ & 31 & 5.39 & 1.202 \\
\hline & $7-9$ & 14 & 5.21 & 1.251 \\
\hline & $>10$ & 19 & 4.79 & 1.619 \\
\hline & Total & 451 & 4.80 & 1.637 \\
\hline & Do not buy & 65 & 4.60 & 1.628 \\
\hline & $<1$ & 148 & 5.09 & 1.659 \\
\hline & $1-3$ & 174 & 5.33 & 1.487 \\
\hline \multirow[t]{7}{*}{ GSS2 } & $4-6$ & 31 & 5.68 & 1.107 \\
\hline & $7-9$ & 14 & 5.57 & 1.342 \\
\hline & $>10$ & 19 & 5.37 & 1.739 \\
\hline & Total & 451 & 5.18 & 1.569 \\
\hline & Do not buy & 65 & 3.74 & 1.632 \\
\hline & $<1$ & 148 & 4.43 & 1.508 \\
\hline & $1-3$ & 174 & 4.75 & 1.386 \\
\hline \multirow[t]{4}{*}{ GSS3 } & $4-6$ & 31 & 4.97 & 1.080 \\
\hline & $7-9$ & 14 & 4.93 & 1.141 \\
\hline & $>10$ & 19 & 4.95 & 1.747 \\
\hline & Total & 451 & 4.53 & 1.495 \\
\hline
\end{tabular}

By inspecting the third table which shows the results of the vertising through sport in relation to the frequency of buying univariate analysis, it is clearly noted that there were also statistically significant differences in general attitudes toward ad-

Table 3. Univariate significance of difference in the system of general attitudes towards advertising through sport among respondents with different habits when buying sporting goods in question

\begin{tabular}{ccc}
\hline & F & p \\
\hline GSS1 & 2.528 & .029 \\
GSS2 & 3.093 & .009 \\
GSS3 & 5.888 & .000 \\
\hline
\end{tabular}

Inspecting the next three tables which show the results of the Post Hoc test, will indicate the significance of the differences between the pairs of individual entities with different haAccording to the results that have appeared on the univariate level, statistically significant differences in the individual parabits when buying sporting goods in question for each variable.

meters with all three variables are expectedly noticed.

Table 4. Identification of significant differences in the system of general attitudes toward advertising through sport by utilizing the Post Hoc test between individual entities with different habits when buying sporting goods in question, for the statement "My general opinion is in favour of advertising through

\begin{tabular}{cccccc}
\hline vs & Do not buy & $<\mathbf{1}$ & $\mathbf{1 ~ - 3}$ & $\mathbf{4 - 6}$ & $\mathbf{7 - 9}$ \\
\hline$<1$ & .172 & & & & \\
$1-3$ & .010 & .125 & & & \\
$4-6$ & .003 & .026 & .166 & & \\
$7-9$ & .068 & .230 & .556 & .741 & \\
$>10$ & .287 & .761 & .686 & .207 & .458 \\
\hline
\end{tabular}


The results of the Post Hoc Test in the fourth table point to the fact that in the first statement "My general opinion is in favour of advertising through sports", there are differences primarily among those who do not buy sporting goods, and those that buy sporting goods 1-3 times and 4-6 times per month. Differences also occur among respondents who buy sporting products less than once a month and a group of respondents who do it 4-6 times a month. The most positive outcomes can be observed in groups buying sporting products 4-6 times a month, while the least positive results are noticed in two groups that least buy sports products.

Table 5. Determining significant differences in the system of general attitudes towards advertising through sport by applying Post Hoc test between individual entities with different habits when buying sporting products in question, for the statement "Generally, I consider advertising through sport a good thing"

\begin{tabular}{cccccc}
\hline vs & Do not buy & $<\mathbf{1}$ & $\mathbf{1 - 3}$ & $\mathbf{4 - 6}$ & $\mathbf{7 - 9}$ \\
\hline$<1$ & .033 & & & & \\
$1-3$ & .001 & .180 & & & \\
$4-6$ & .002 & .058 & .248 & & \\
$7-9$ & .034 & .272 & .572 & .832 & \\
$>10$ & .058 & .469 & .913 & .495 & .710 \\
\hline
\end{tabular}

The results of the Post Hoc Test in the fifth table point of the other entities. The most positive outcomes can be obout that, in other words, "Generally, I consider advertising served in groups buying sports products 4-6 times a month, through sport a good thing.", the differences appear first of while the least positive results are noticed in the group that all among those who do not buy sports products and most purchases sports products the least.

Table 6. Determining significant differences in the system of general attitudes toward advertising through sport by applying Post Hoc test between individual entities with different habits when buying sporting products in question, for the statement: "Generally, do you like or dislike advertising through sport?"

\begin{tabular}{cccccc}
\hline vs & Do not buy & $<\mathbf{1}$ & $\mathbf{1 - 3}$ & $\mathbf{4 - 6}$ & $\mathbf{7 - 9}$ \\
\hline$<1$ & .002 & & & & \\
$1-3$ & .000 & .045 & & & \\
$4-6$ & .000 & .060 & .450 & & \\
$7-9$ & .006 & .218 & .664 & .933 & \\
$>10$ & .002 & .142 & .581 & .962 & .971 \\
\hline
\end{tabular}

The results of the Post Hoc Test in the sixth table indicate that in the third claim "Generally, do you like or dislike advertising through sport", there are differences primarily among respondents who don't buy sporting goods and all other groups. Differences also appear among those who do not buy sporting goods and entities that do it 1-3 times a month. The most positive outcomes can be observed in groups buying sporting products 4-6 times a month, while the least positive results are noticed in two groups that buy sporting products the least.

\section{Discussion}

Since the results showed that respondents have a very positive attitude towards advertising through sport, which is confirmed with the high value of the arithmetic mean for all three variables, and that almost two thirds of respondents have a positive attitude towards advertising through sport, which is reflected in extremely negative values of asymmetric measures, it should be emphasized that these results are consistent with the results of the previous research (Molnar, Lilic, Popovic, Akpinar, \& Jaksic, 2011; Popovic, Jaksic, Matic, Bjelica, \& Maksimovic, 2014; Popovic, Bjelica, Georgiev, \& Akpinar, 2011), and that there are no significant differences that are worth mentioning. The obtained results also show that respondents living in different locations, such as the United States, Turkey, Montenegro, Serbia and Bosnia and Herzegovina, have positive attitudes toward advertising through sport while, however, for the sake of comparison, it is worth mentioning that, according to Mittal (Bjelica et al.,

2016a; Bjelica et al., 2016c), various studies point to negative attitudes when advertising products in traditional industries is concerned. Therefore, it is more than evident that the use of sports in modern business communication has influenced a significant change in the general attitude of consumers when advertising is concerned, and the recognition of the attractiveness of sports has allowed business organizations to approach sporting consumers and affect their behaviour in a much more subtle way.

By determining the difference in the general attitudes of respondents toward advertising through sports compared to the frequency of purchasing sports goods, this study found differences in attitudes among respondents who have reported different habits of shopping sporting goods. These differences appeared in all three variable at the univariate level. In all three reportable "My general opinion is in favor of advertising through sport", "Generally, I think that advertising through sport is a good thing", and "Generally, do you like or dislike advertising through sport?", the most positive results are noticed in the group that buys sports products 4-6 times a month, while the least positive results are noticed in those groups that do not buy sports products. Based on the statistical analyses, significant differences were found at the multivariate level, as well as among all three variables at the univariate level of significance of $\mathrm{p}=.05$. It is also interesting to point out that the vast majority of respondents identified with one out of two entities, 322 (out of 451), primarily with consumers who buy sports products less than once a month and with consumers who buy sports products once or three times a month. 
Future research should focus on a larger number of respondents, as a significant number of respondents group into a category with fewer purchases of sports products during the month, especially because some differences are expected to be interesting and useful for both theory and practice.

\section{Acknowledgements}

There are no acknowledgements.

\section{Conflict of Interest}

The authors declare that there are no conflicts of interest.

Received: 9 September 2018 | Accepted: 12 November 2018 | Published: 01 February 2019

\section{References}

Bajramovic, I., Zoric, G., \& Masanovic, B. (2018). Attitudes of Consumers from the Sarajevo Canton in Bosnia and Herzegovina toward Advertising through Sport among the Frequency of Watching Sports Events. Journal of Anthropology of Sport and Physical Education, 2(2), 43-7.

Bjelica, D., Gardasevic, J., Vasiljevic, I., \& Popovic, S. (2016a). Ethical Dilemmas of Sport Advertising. Sport Mont, 14(3), 41-3.

Bjelica, D., Gardasevic, J., Vasiljevic, I., \& Popovic, S. (2016b). Ethical dilemmas of sport advertising. In Book of Abstracts of the 13th International Scientific Conference on Transformation Process in Sport "Sport Performance" (41), Podgorica: Montenegrin Sports Academy

Bjelica, D., \& Popovic, S. (2015). Evolution of advertising with a specific retrospection at sport advertising. Sport Mont, XIII(43-44-45), 35-41.

Bjelica, D., \& Popovic, S. (2015b). Evolution of Advertising with a Specific Retrospection at Sport Advertising. In Book of Abstracts of the 12th International Scientific Conference on Transformation Process in Sport "Sport Performance" (60-61), Podgorica: Montenegrin Sports Academy.

Bjelica, D., Popovic, S., Jaksic, D., Hadzic, R., \& Akpinar, S. (2014). How Does Advertising through Sport Work? Evidence from Turkey. In Proceedings book of the 7th International Scientific Conference on Kinesiology "Fundamental and Applied Kinesiology - Steps Forward" (477). Opatija: University of Zegreb, Faculty of Kinesiology.

Bjelica, D., i Popovic, S. (2011). Stavovi potrosaca prema reklamiranju sportu u odnosu na ucestalost posmatranja sportskih dogadjaja. Sportske nauke i zdravlje, 1(2), 114-119.

Gardasevic, J., Bajramovic, I., \& Masanovic, B. (2018). Attitudes of Consumers from the Sarajevo Canton in Bosnia and Herzegovina toward Advertising through Sport among the Question how Often they Participate in Sports Activities. Journal of Anthropology of Sport and Physical Education, 2(2), 37-41.

Klacar, M., \& Popovic, S. (2010). Reklamiranje u sportu kao efektivno sredstvo savremene komunikacije. Teme, 4, 1219-30.

Masanovic, B. (2018). Attitudes of consumers from Autonomous Province of Vojvodina toward advertising through sport in relation with the frequency of watching sports events. Sport Mont, 16(3), 91-96. doi: 10.26773/smj.181016

Milovic, N., Corluka, M., \& Masanovic, B. (2018). Attitudes of consumers from Podgorica toward advertising through sport among the frequency of watching sports events. Journal of Anthropology of Sport and Physical Education, 2(2), 71-6. doi: 10.26773/jaspe.180413
Molnar, S., Lilic, Lj., Popovic, S., Akpinar, S., \& Jaksic, D. (2011). Attitudes of various demographic groups toward advertising through sport at METU. Facta Universitatis, Series: Physical Education and Sport, 9(3), 25563.

Molnar, S., Masanovic, B., \& Bjelica, D. (2018). Attitudes of consumers from University of Novi Sad toward advertising through sport among the frequency of watching sports events. Journal of Anthropology of Sport and Physical Education, 2(3), 9-14. doi: 10.26773/jaspe.180702

Muratovic, A., Bjelica, D., \& Popovic, S. (2014). Examining beliefs and attitudes toward advertising through sport among montenegrin consumers. Facta Universitatis, Series: Physical Education and Sport, 12(2), 95-104.

Popovic, S., \& Milasinovic, R. (2016). Model of Advertising Communication in Sport. Sport Mont, 14(1), 33-8.

Popovic, S. (2015). Sport Nowadays (In Montenegrin). In D. Bjelica (Ed.), Ad vertising Role of Sponsorship in Modern Sport (111-6). Podgorica: Montenegrin Sports Academy.

Popovic, S., Jaksic, D., Matic, R., Bjelica, D., \& Maksimovic, N. (2015). Examining Beliefs and Attitudes toward Advertising through Sport among Serbian Consumers. Studia Sportiva, 9(1), 225-31.

Popovic, S., Matic, R., Milasinovic, R., Jaksic, D., \& Bjelica, D. (2015a). Stavovi srbijanskih potrosaca prema reklamiranju u sportu u odnosu na ucestalost bavljenja sportskim aktivnostima. Sport Mont, 13(43,44,45), 50-6.

Popovic, S., Matic, R., Milasinovic, R., Jaksic, D., \& Bjelica, D. (2015b). Attitudes of Serbian Consumers toward Advertising through Sport among the Question How Often They Participate in Sports Activities. In Book of Abstracts of the 12th International Scientific Conference on Transformation Process in Sport "Sport Performance" (58-9), Podgorica: Montenegrin Sports Academy.

Popovic, S., Jaksic, D., Matic, R., Bjelica, D., \& Maksimovic, N. (2014). Examining Beliefs and Attitudes toward Advertising through Sport among Serbian Consumers. In Book of abstracts of International conference "Economics and Management of Sports 2014" (11-2). Brno: Faculty of Sports Studies.

Popovic, S., Bjelica, D., Jaksic, D, \& Georgiev, G. (2013). How does Advertising Through Sport Work? Evidence from Montenegro. In Book of Abstracts of the $18^{\text {th }}$ Annual Congress of the European College of Sport Science (444-5), Barcelona: National Institute of Physical Education of Catalonia.

Popovic, S. (2011). Reklamiranje u sportu kao efektivno sredstvo savremene poslovne komunikacije. Neobjavljena doktoska disertacija, Novi Sad: Univerzitet u Novom Sadu.

Popovic, S. (2011). The attitudes toward sport advertising among the question how often consumers purchase sporting goods. Sport Mont, IX(2829-30), 140-147.

Popovic, S., Bjelica, D., Georgiev, G., \& Akpinar, S. (2011). Comparison of attitudes toward advertising through sport between Montenegrin and Turkish stakeholders. In Proceedings book of the 6th International Scientific Conference on Kinesiology "Integrative Power of Kinesiology" (612). Opatija: University of Zegreb, Faculty of Kinesiology.

Stupar, D., Gardasevic, J., \& Masanovic, B. (2018). Attitudes of consumers from Educons university toward advertising through sport among the frequency of watching sports events. Journal of Anthropology of Sport and Physical Education, 2(3), 131-136. doi: 10.26773/jaspe.180723 